\title{
Implant-Supported Prosthesis for Edentulous Patient Rehabilitation. From Temporary Prosthesis to Definitive with a New Protocol: A Single Case Report
}

\author{
Roberto Scrascia ${ }^{1}$, Luca Fiorillo ${ }^{2, *}$, , Valeria Gaita ${ }^{3}$, Luigi Secondo ${ }^{4}$, Fabiana Nicita ${ }^{2}$ and \\ Gabriele Cervino ${ }^{2}$ (D) \\ 1 Private Practice, 74121 Taranto, Italy; roberto.scrascia@gmail.com \\ 2 Department of Biomedical and Dental Sciences and Morphological and Functional Imaging, \\ Messina University, 98122 Messina ME, Italy; lfiorillo@unime.it (F.N.); gcervino@unime.it (G.C.) \\ 3 Department of Neurosciences, Reproductive and Odontostomatological Sciences, \\ University “Federico II" of Naples, 80131 Naples, Italy; valegaita93@gmail.com \\ 4 Dental Technician, Private Practice, 74121 Taranto, Italy; lu.secondo@alice.it \\ * Correspondence: 1fiorillo@unime.it
}

Received: 20 January 2020; Accepted: 5 February 2020; Published: 10 February 2020

\begin{abstract}
This case study concerns a patient who had lost all of his teeth, needing a rehabilitation with total prosthesis, who went to the dentist looking for help to overcome psycho-physical trauma and to overcome functional and social problems related to being a prosthesis wearer. Tooth loss occurs most in old age, even if it is not a direct consequence of aging. The rehabilitation of oral functions allows the patient to speak, chew, smile and feel confident in his own aesthetics and therefore improve, even a lot, his well-being in social relations. It is very important in oral rehabilitations to evaluate their type and therapeutic timing. This study stems from the idealization of a new protocol to simplify the supported oral rehabilitations. In this manuscript, a patient was considered and shown according to a complete photographical documentation all the phases. Rehabilitation included the use of Osstem (Osstem, Seoul, Korea) and equator type abutments (Rhein83, Bologna, Italy). This manuscript claims to represent the first of a whole series of cases demonstrating the utility of this protocol.
\end{abstract}

Keywords: prosthodontic; dentistry; dental implant; protocols; QoL

\section{Introduction}

In this article a clinical case will be presented, reporting the procedures of diagnosis and treatment of a patient in terminal dentition. The aim is to rehabilitate it with simple and predictable prosthetic solutions able to provide benefit to the patient both from a clinical and psychological point of view. The collapse of the vertical dimension found at a careful clinical examination is the result of a long period during which the patient neglected his mouth (Figure A1). It was interesting to listen his requests concerning functional difficulties, as the patient expressed the need to go back to eating chewing, and without aesthetic difficulties, as his wife explicitly requested an improvement in the harmony of the smile [1-3]. Edentulism, that is, total or partial tooth lessness, has consequences, not only from the aesthetic point of view, but also on general health. The edentulous patient, who is missing one or more dental elements, should be well informed and treated with an often multidisciplinary approach of several specialist doctors on his specific case [3].

Complex rehabilitations for partial or total edentulism should be examined with a global approach that starts from the patient's health, from the causes that generated tooth loss, to then proceed with global care plans that take all these factors into consideration in order to ensure a predictable result. 
The main objective was to design an implant-prosthetic treatment revolutionizing patient smile line for their benefit and oral-related quality of life.

\section{Materials and Methods}

Extraoral examination showed the typical morphology of the face, characteristic of patients who are losing all their dental elements. The vermillion of the lips was thinned and the nasolabial folds were more pronounced than the numerous folds of the face due to the loss of many dental elements and of the bone support that once supported the soft tissues of the lower third of the face.

After having examined several therapeutic options, in agreement with the patient, the treatment plan included a lower overdenture prosthesis type of implant-supported tissue and, in the maxilla, a hybrid fixed total prosthesis, like Toronto, with a new systematic use the same prosthetic components for both arches.

Our operational sequence included the classic steps, performed in order to extract all the information from our patient's mouth:

- First panoramic footprints;

- DV detection;

- Facial arch;

- Articulator assembly;

- Mounting of the teeth, a key step especially in the realization of a temporary prosthesis.

To modify the smile line, it was necessary to program a prosthetically guided osteotomy through the creation of a transparent resin template to report the measurements of the osteotomy performed on the plaster model of the patient's mouth (Figure A2).

The extraction of the elements and of the radicular residues in the lower arch was followed by a prosthetically guided osteotomy and the contextual insertion of the implants using an analogue smart tool, the parallel kit (Osstem, Seoul, Korea) (Figure A3). This instrument is a steel fork, adjustable according to the shape of the arch (Figure A4). It foresees a series of holes at a certain distance that act as a guide for the positioning of the implants based on the individual prosthetic requirement (Figure A5). It is fixed with a pin after passing a pilot drill at the midline level. Then, we proceeded with the preparation of the planned implant sites. Two $4 \mathrm{~mm} \times 10 \mathrm{~mm}$ TSIII implants (Osstem, Seoul, Korea) were inserted (Figure A6). The implant fixtures were inserted about two millimeters below the ridge as protocol in the post-extraction sites. The healing screws were placed on the implants, thus resorting to one-stage surgery, in order to shorten the duration of the implant healing phases [4-7].

The sutures were removed 7 days after surgery. Close follow-ups are recommended in order to promote optimal tissue healing. During follow-ups, the pressure zones of the temporary prosthesis were checked and any compression on the healing screws relieved to avoid stressing the implants excessively during the osseointegration phase (Figure A7).

A key element for the success of implant-prosthetic rehabilitation is the patient's maintenance of optimal oral hygiene (Figure A8).

Regarding the upper arch, the treatment plan followed the diagnosis made with the assembly of the teeth. A temporary prosthesis positioned on the day of the extraction of the dental elements was created, duplicated and used as a surgical template for the insertion of four hands-free implants prosthetically guided by the assembly of the teeth (Figure A9). The fixtures that were placed were $4 \times 11.5 \mathrm{~mm}$ measuring implants (Osstem, Seoul, Korea) on top (Figure A10). Once the operation was completed, the temporary prosthesis was delivered. The duplication of the upper and lower temporary prostheses was been preserved as these would be used later for the final impression taking. Even in the maxilla, one-stage surgery was chosen with the insertion of healing abutments at the time of implant surgery. The upper temporary restoration followed the same steps as the lower restoration. 
After the expected three months, a period in which the implants completed their osseointegration process and the soft tissues stabilized, the final implant-prosthetic rehabilitation proceeded (Figure A11). The patient provided important feedback on chewing, phonetics and aesthetics which, in addition to the information extrapolated from the provisional prostheses, made it possible not to repeat the previously performed steps. The temporary restorations were duplicated in transparent resin in order to transfer the information regarding the position of the implants, the intermaxillary relationships, the position of the teeth and the occlusion to the laboratory, through the codified technique of "cross mounting". For the impression of the lower arch, the chosen material was a polysulfur, and for the upper impression, heavy and light Vinylsiloxanether (Figure A12) were chosen.

The laboratory, after assembling the models in the articulator and the realization of the analogical silicone masks, exploited the previously established position of the teeth to build a new prosthesis with definitive teeth and materials [8-11].

The impressions' control key represents a step that could not be ignored as it verifies whether the position of the implants on the model is true or not to the real one; another technique in use is that of the plaster control key.

For the superior, an anatomical $\mathrm{Cb}-\mathrm{Cr}$ (Cobalt-Chromium) fusion was prepared which would then be glued onto the towers of the OT Bridge (Rhein83, Bologna, Italy) fixed prosthesis system; the next step involved resining (Figure A13). For the mandible, instead, a metal reinforcement was created, a passage always recommended to be premanufactured with reduced contraction (Rhein83, Bologna, Italy). Using the same low-profile abutment OT Equator (Rhein83, Bologna, Italy) both the lower and upper arches were rehabilitated with different solutions. In clinical practice, clinicians always look for solutions that could simplify the steps and make the procedures leaner without errors. The development of materials helps us in this. For example, for subsequent clinical cases it was decided to vary the protocol and insert the OT Equator (Rhein83, Bologna, Italy) already at the time of surgery with its healing abutment and then use the dedicated transfer. In this way, further components could be eliminated, making the work-flow even easier. Passages and exchanges of information with the dental laboratory are of fundamental importance, as are meetings in order to elaborate a treatment and speak a common language for the good of the patient and practicality in the daily clinic [12-17]. The superior prosthesis, in its delivery, was inserted and kept in place alone according to the OT Bridge method, having the Seeger inside the abutment with a seal of $7 \mathrm{~kg}$, which allows it to lock it with a click (Figure A14). The screws were then tightened to $15 \mathrm{~N} \mathrm{~mm}$ and the union of the screws with the Seeger ensured an excellent retention of the retention system over time. The inferior prosthesis was delivered without loading the attachments, being a prosthesis with a mucous support with the relative time (a few days or weeks) for its natural stabilization (Figure A15).

After the controls in the following days to avoid the occurrence of any decubitus of the lower prosthesis, with symptoms completely absent, we proceeded with the loading of the attacks (Figures A16-A18). The load of the OT Equator (Rhein83, Bologna, Italy) was directly based on the positioning of the separator disks on the attacks to eliminate the undercuts, positioning the metal containers with the yellow $500 \mathrm{~g}$ retentive matrix inside and fixing the same on the patient with acrylic resin (Figure A19).

On the prosthesis, vent holes were made lingually to eliminate excess resin during the functionalization of the attachments. Hardened resin excesses were removed and polishing was started. Spreading Vaseline in the critical areas of the prosthesis helped us to not damage the anatomical areas detected with the impression. After about 10 days, the yellow matrices were replaced with the pink $1.2 \mathrm{~kg}$, which have longer durability time. The follow-up allows to evaluate the success of a prosthetic treatment. The implant-retained and tissue-supported overdenture is a reproducible implant-prosthetic protocol particularly appreciated by patients. It is absolutely important not to underestimate the periodic references, as a prosthesis with an extended mucous support will need cadenced rebasing to guarantee the continuous and optimal functioning of the same, otherwise retentive matrices will quickly meet with wear or, in cases of strong negligence on the part of the patient, the 
breaking the balance of our retentive system with loss of bone support around the implant due to overload. The use of two implants, even with reduced diameter, to support a mandibular overdenture is a safe and predictable protocol. In fact, different studies highlight its long-term predictability [18-21].

\section{Results and Discussion}

The overdenture is a removable prosthesis stabilized on dental implants, light and not bulky; the upper one may not have a palate. Many patients find it difficult to keep their removable prosthesis stable, especially that of the jaw, or they have difficulty with the palatal plate in the case of the upper arch. Overdentures are a type of removable, metal-reinforced resin prosthesis for patients who have lost or are about to lose all their teeth and for patients with unstable mobile prostheses. Overdenture prostheses are anchored on titanium dental implants and have special attachments (female), inside which are housed just as special attachments (male) present on the ends of the implants. These "links" could have the shape of a sphere, a cylinder or a bar. The prostheses are removable so that they could be easily cleaned (they are easy washable prostheses), an important advantage, but at the same time they are perfectly stable during chewing and phonesis. The simplest type of implant-prosthetic rehabilitation is that in which two or four dental implants are positioned in the anterior area of the jaw and/or maxilla [10]. A functional situation is thus obtained in which the prosthesis is anchored to the implants anteriorly and is supported against the mucosa at the rear. If the residual bone is poorly represented, instead of traditional implants, the so-called mini-implants can also be used, which have a smaller footprint and a lower cost than traditional implants. In some cases, the old prosthesis can also be used with mini-implants, adding further economic savings [21-23]. An explanation was provided to the patient regarding hygienic maintenance with soft brushes and toothbrushes and also the need to dismantle maintenance work each year which will increase the long-term survival of our implant-prosthetic work (Figure A20).

\section{Conclusions}

In conclusion, an important step in an implant-prosthetic rehabilitation is the collection of information and the diagnosis of the treatment plan. Fortunately, for the development of this project, implant systems and prosthetic components have been chosen that are reliable and simple to use, making our daily clinical practice, both in the studio and in the laboratory, faster and more productive (Figure A21).

Author Contributions: Conceptualization, R.S.; methodology, L.S.; writing—original draft preparation, R.S. and V.G.; writing-review and editing, L.F.; visualization, F.N.; supervision, L.F.; project administration, G.C. All authors have read and agreed to the published version of the manuscript.

Funding: This research received no external funding.

Conflicts of Interest: The authors declare no conflict of interest. 


\section{Appendix A}

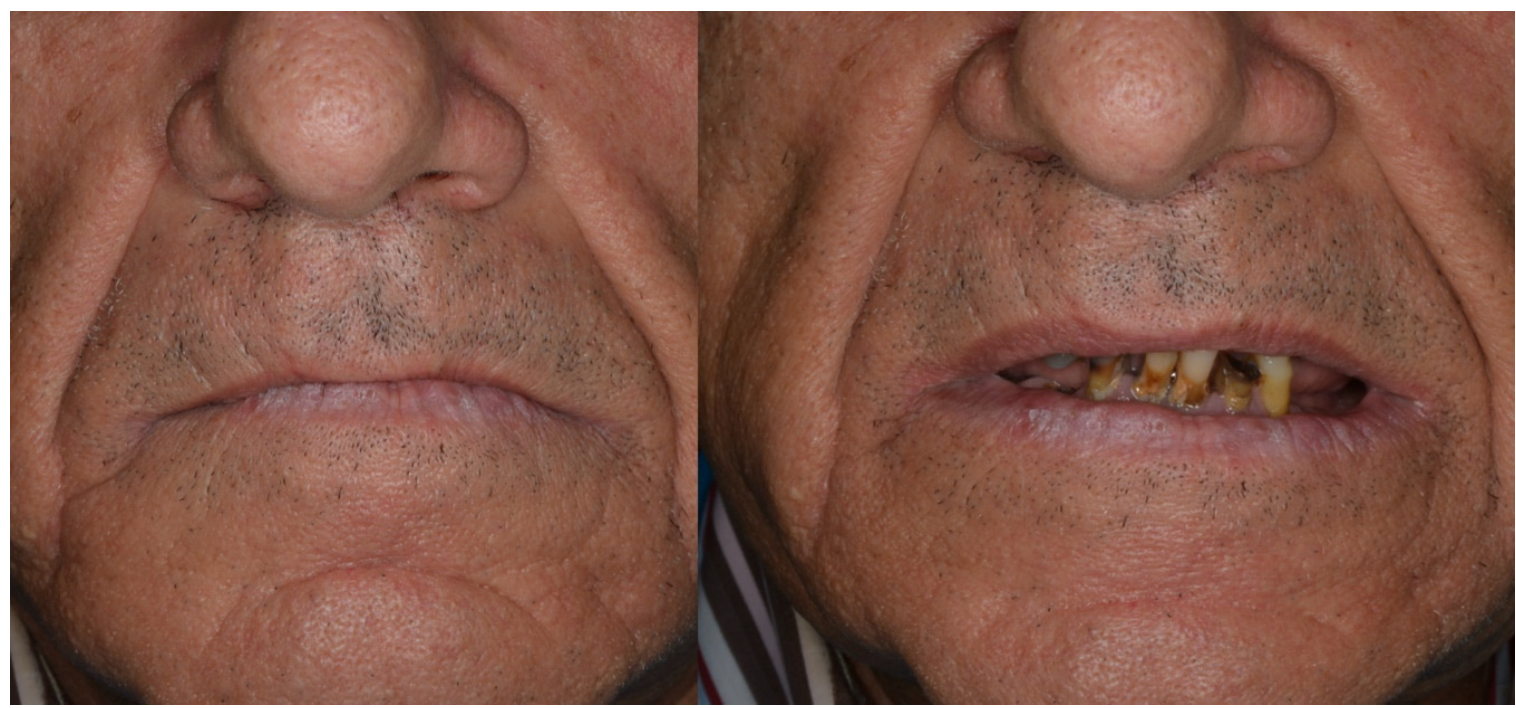

Figure A1. Patient's extraoral examination.

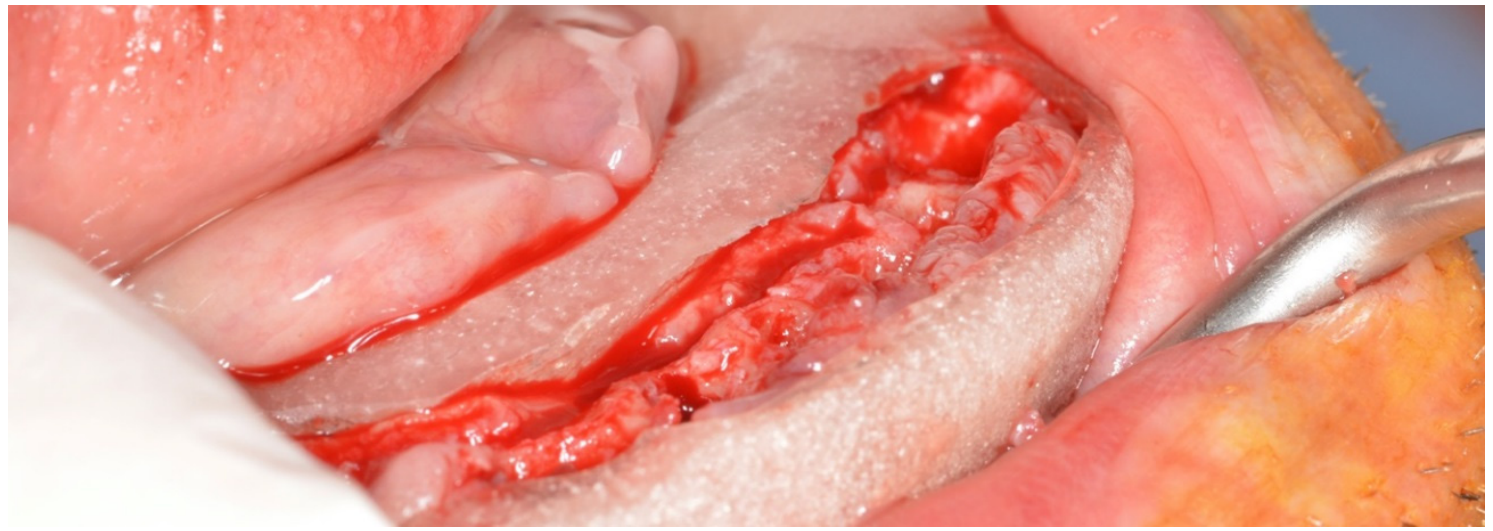

Figure A2. Osteotomy detail.

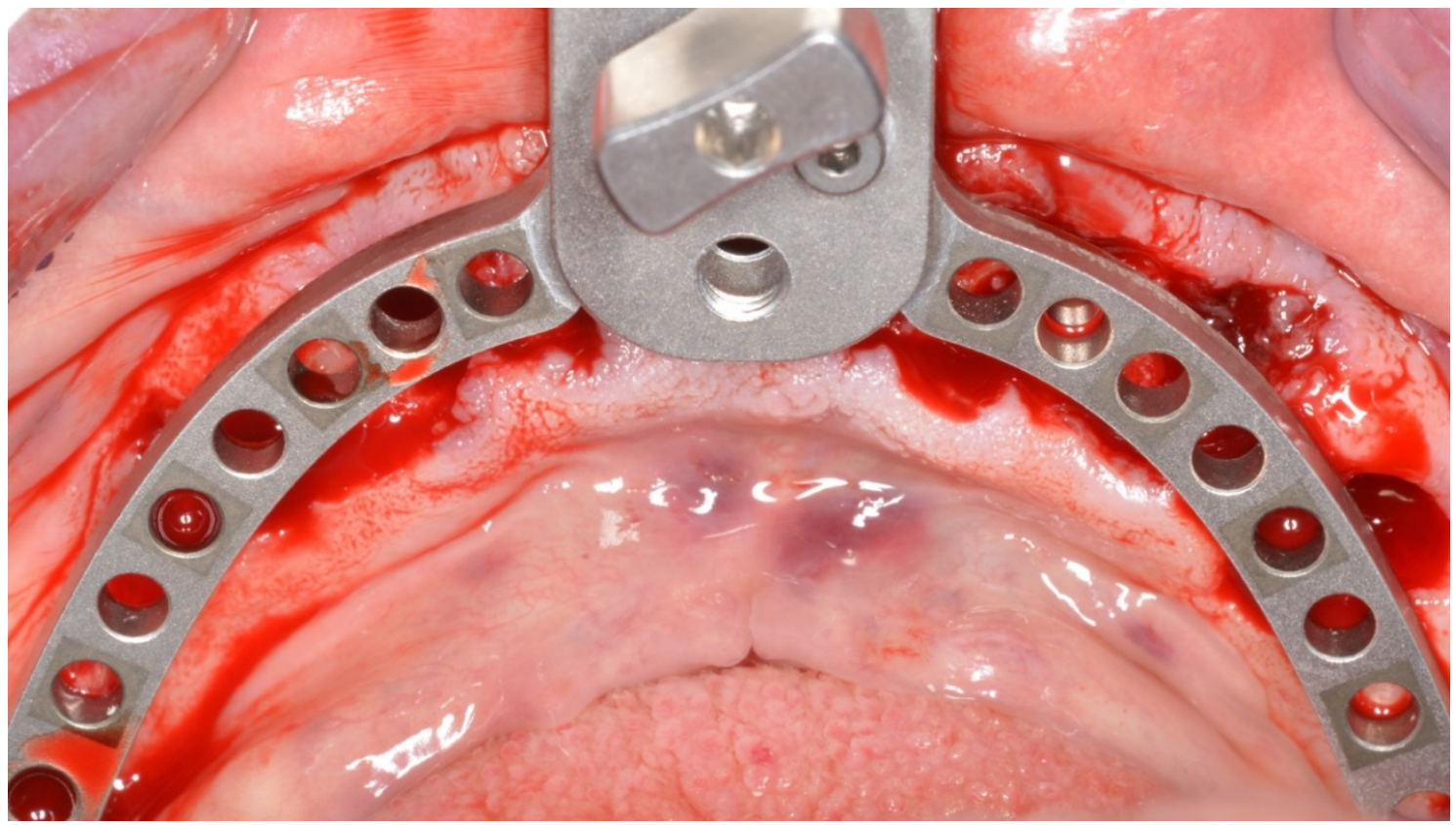

Figure A3. Parallel Kit (Osstem, Seoul, Korea). 


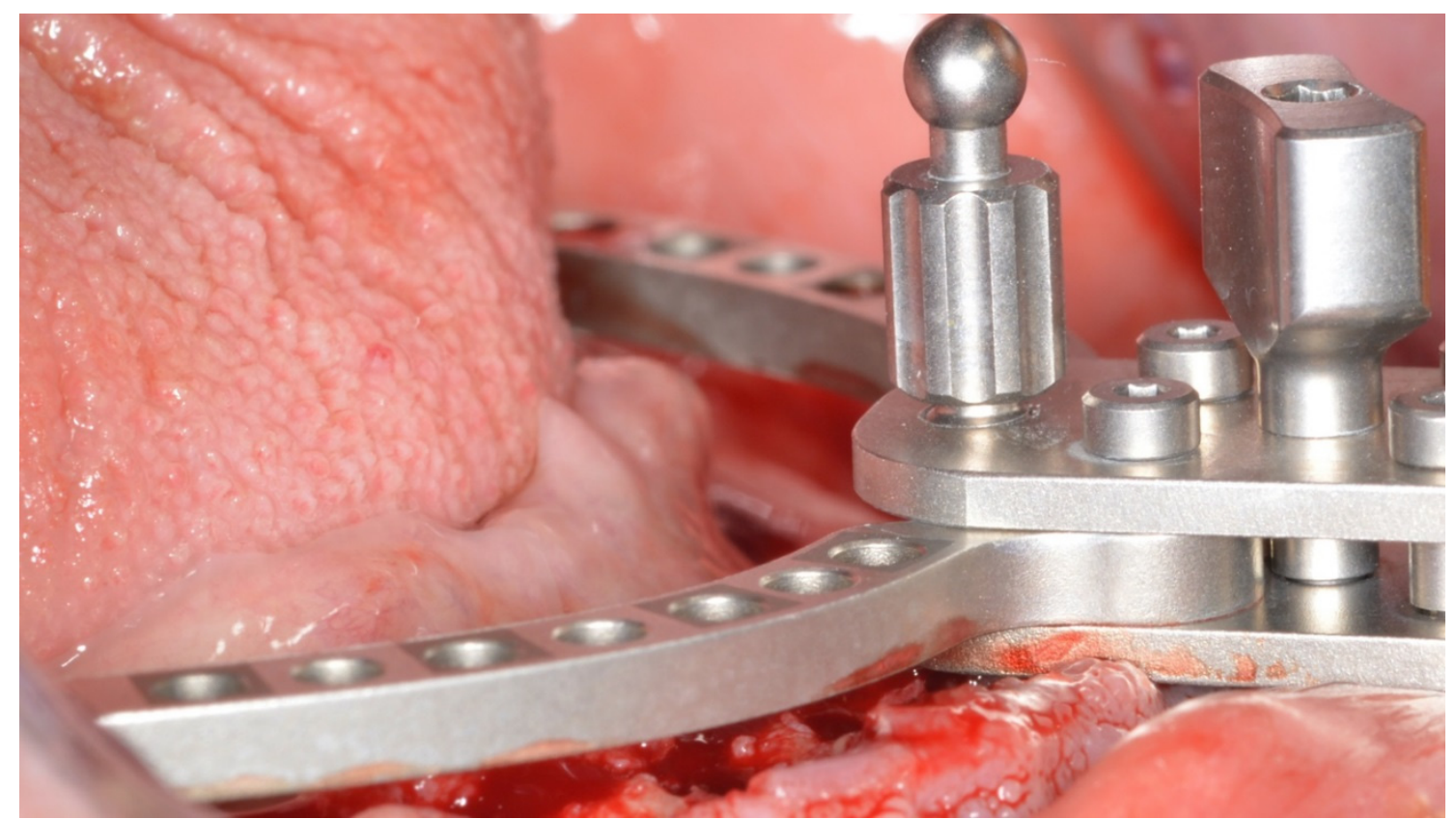

Figure A4. Parallel Kit (Osstem, Seoul, Korea).

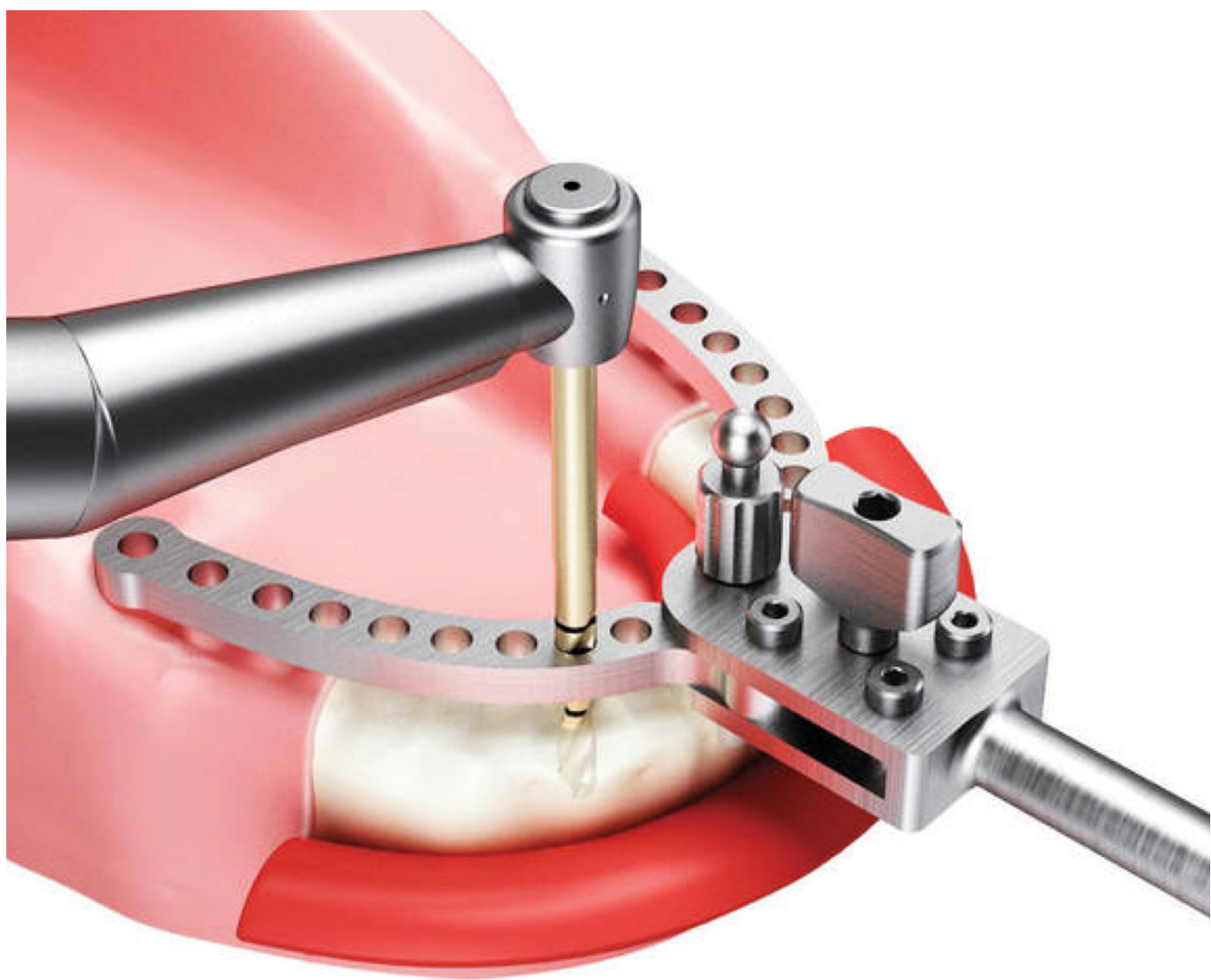

Figure A5. Parallel Kit (Osstem, Seoul, Korea) using scheme. 


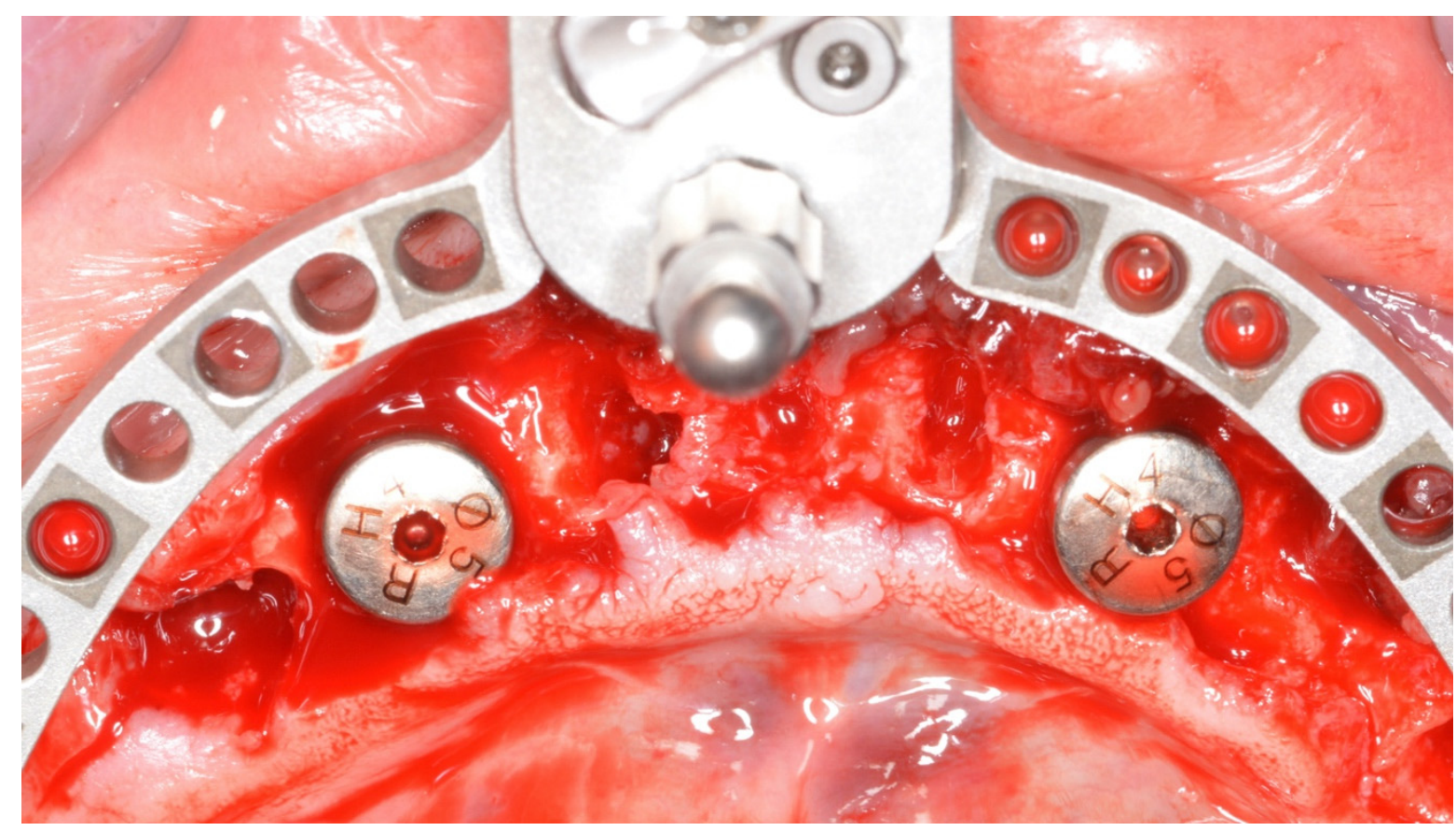

Figure A6. Parallel Kit (Osstem, Seoul, Korea) with inserted fixtures.

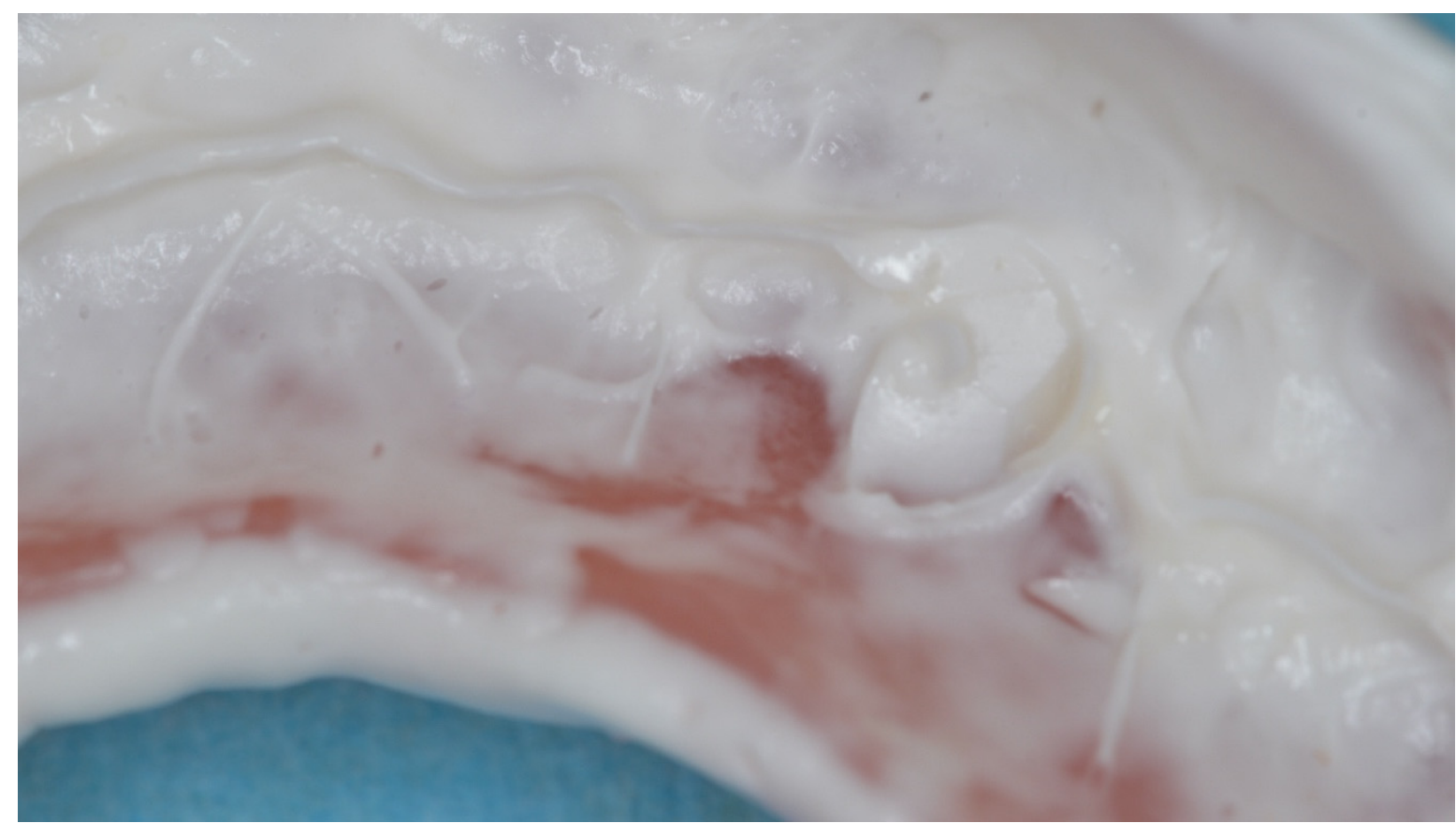

Figure A7. Temporary prosthesis fit check. 


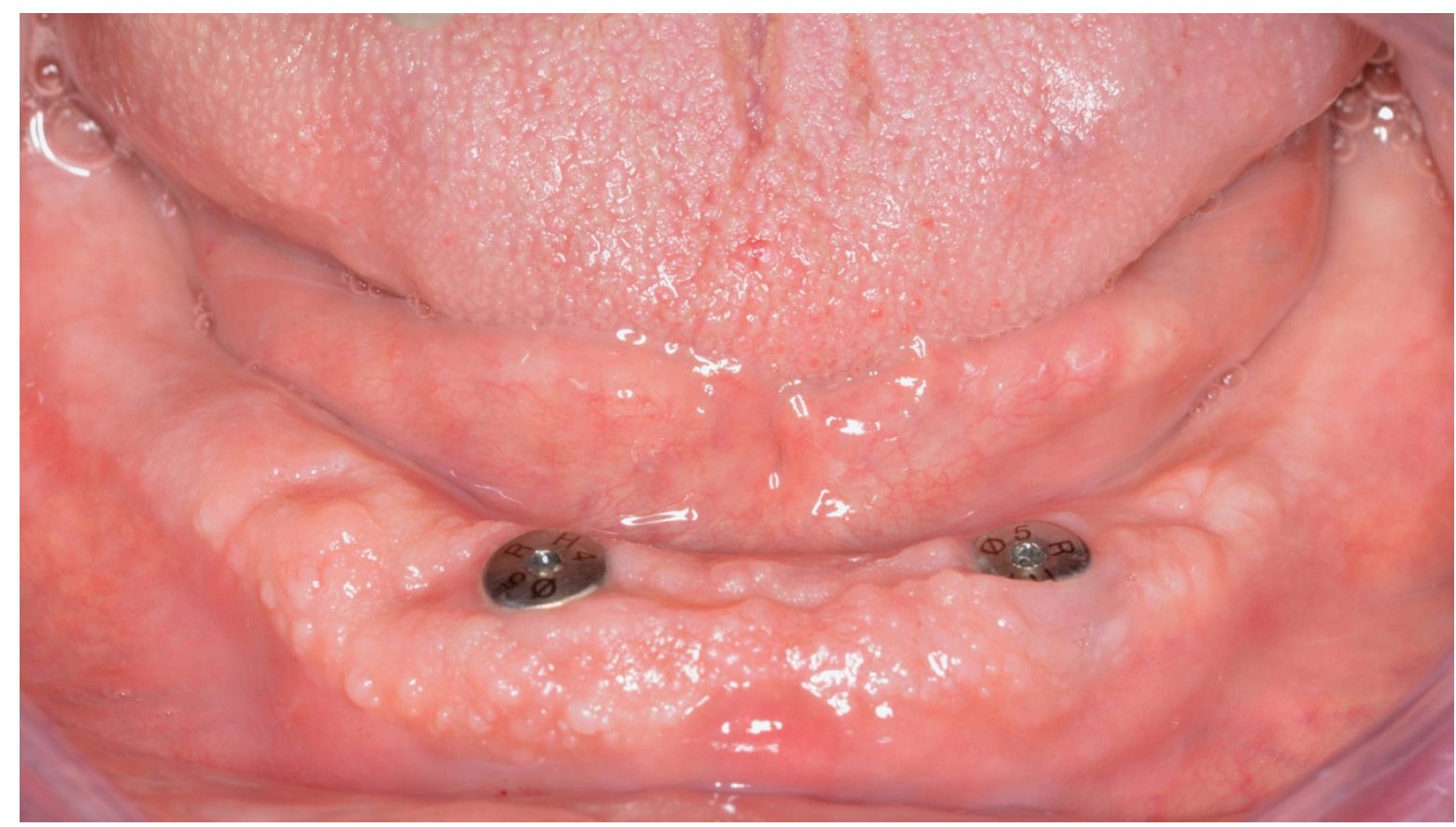

Figure A8. Healthy peri-implant tissue.

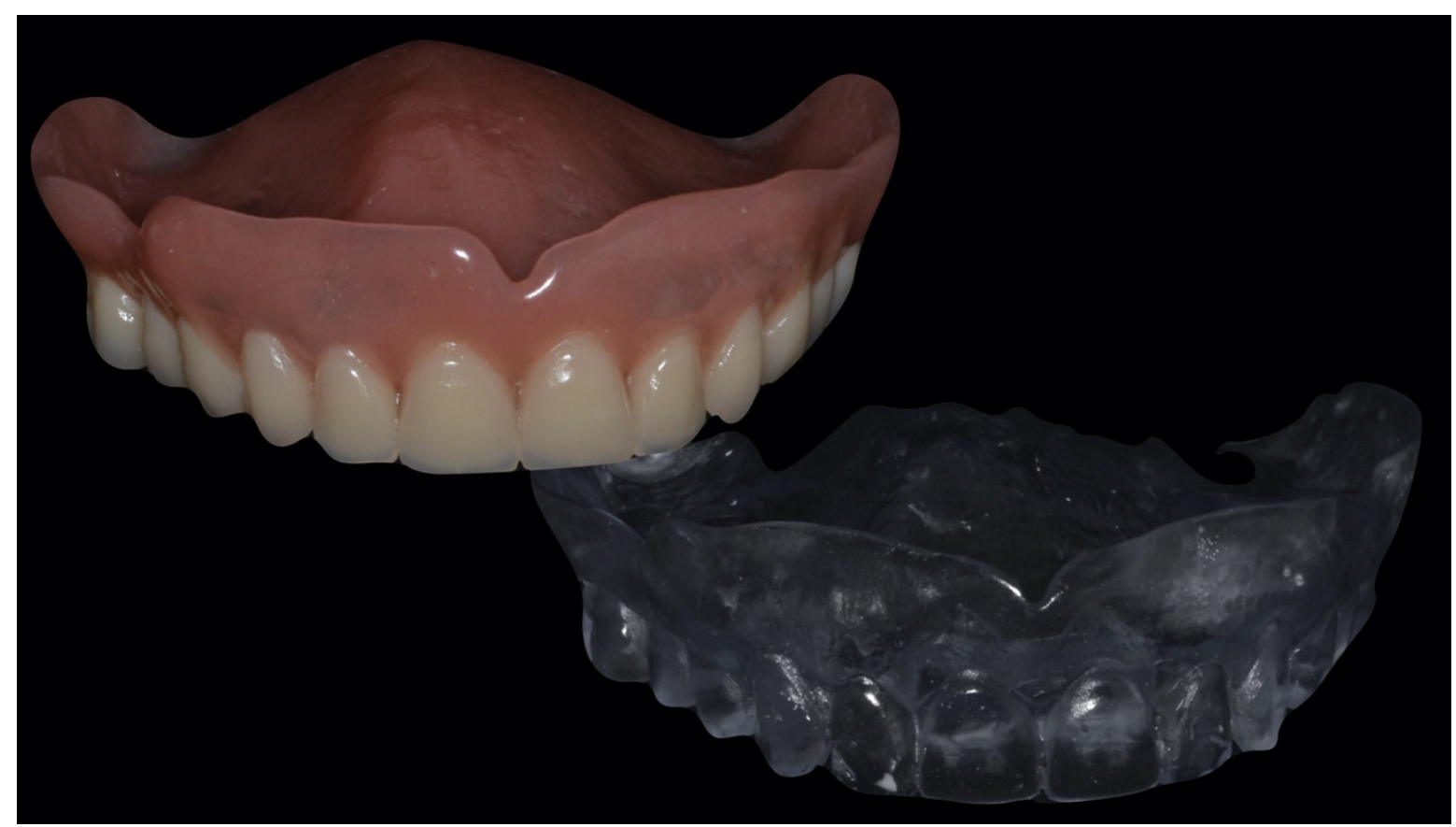

Figure A9. Surgical template for guided implant insertion. 


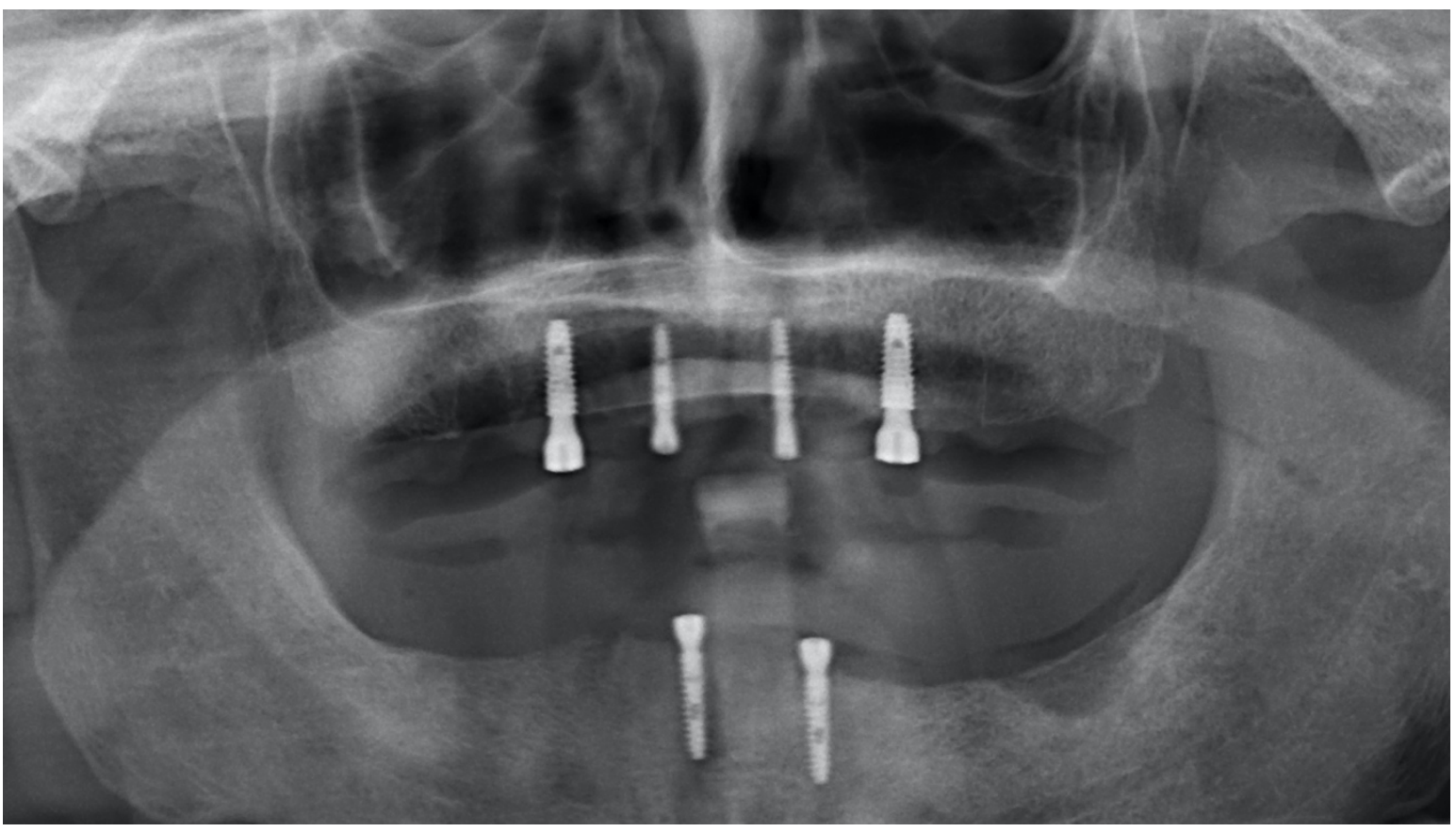

Figure A10. Radiographical examination of dental implant (Osstem, Seoul, Korea) fixture.

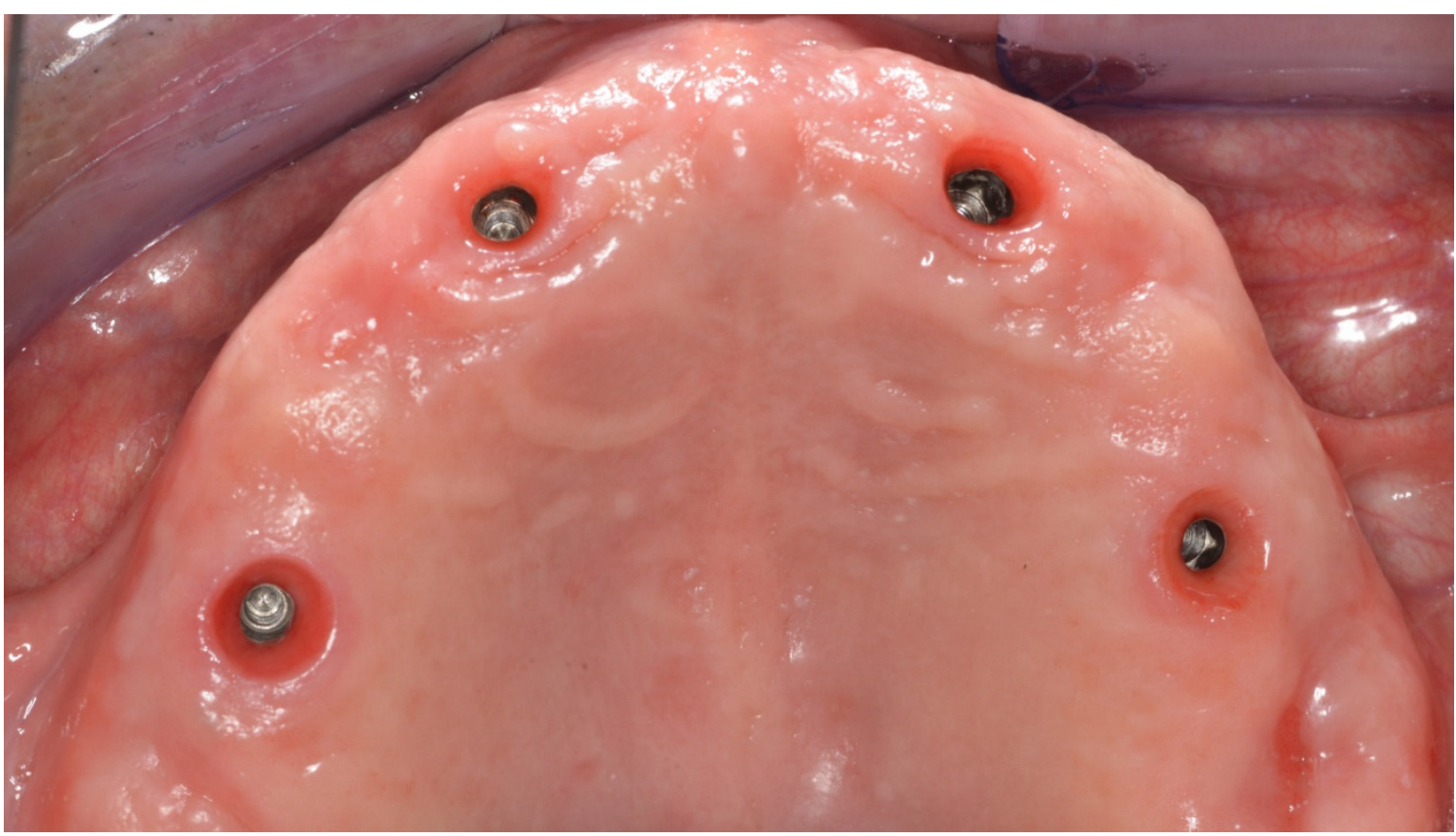

Figure A11. Healthy peri-implant tissue after healing abutment removal. 


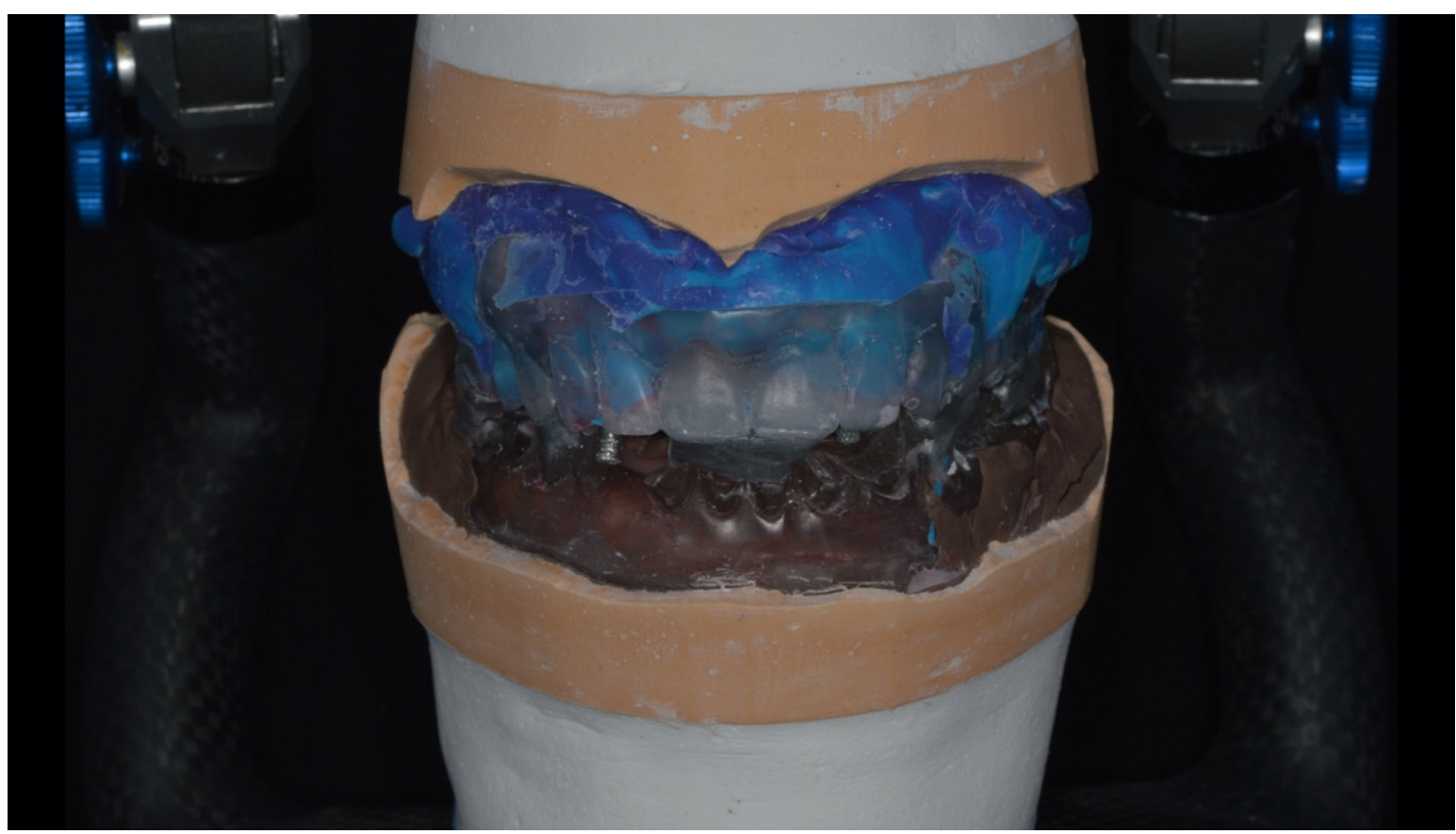

Figure A12. Dental technician production phase.

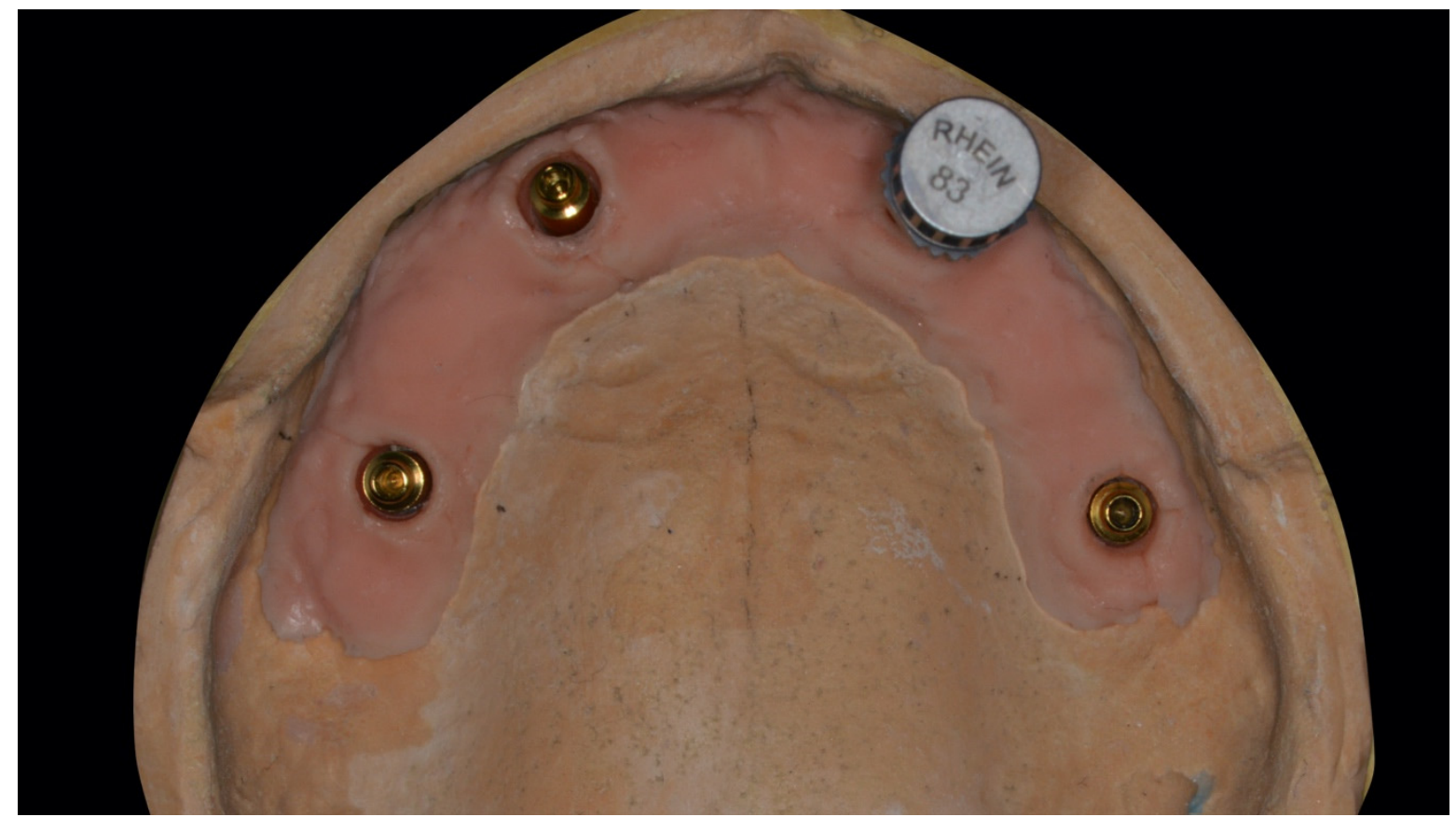

Figure A13. Dental technician production phase. 


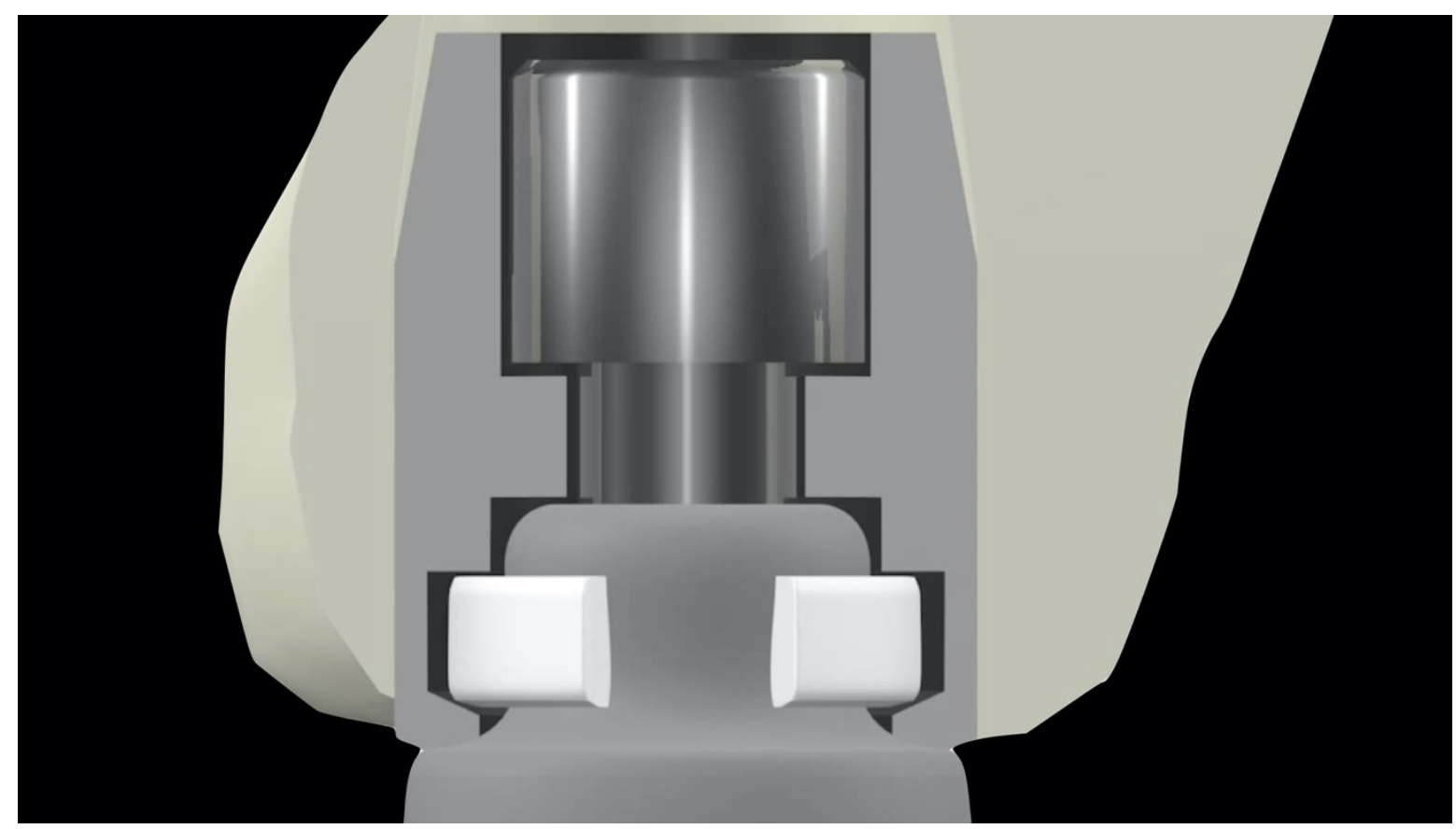

Figure A14. Seeger seal inside OT equator (Rhein83, Bologna, Italy).

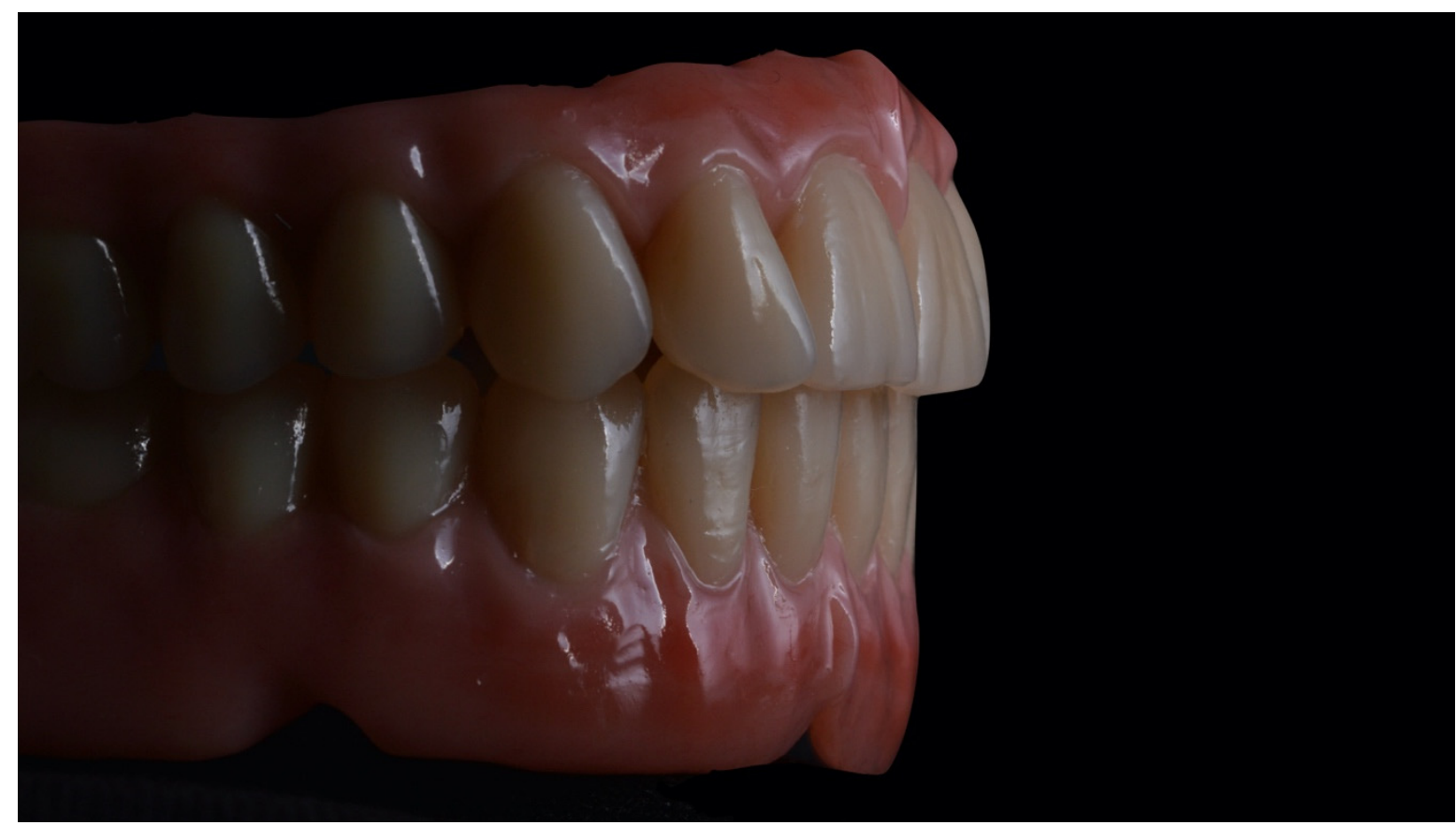

Figure A15. Upper and lower prosthesis. 


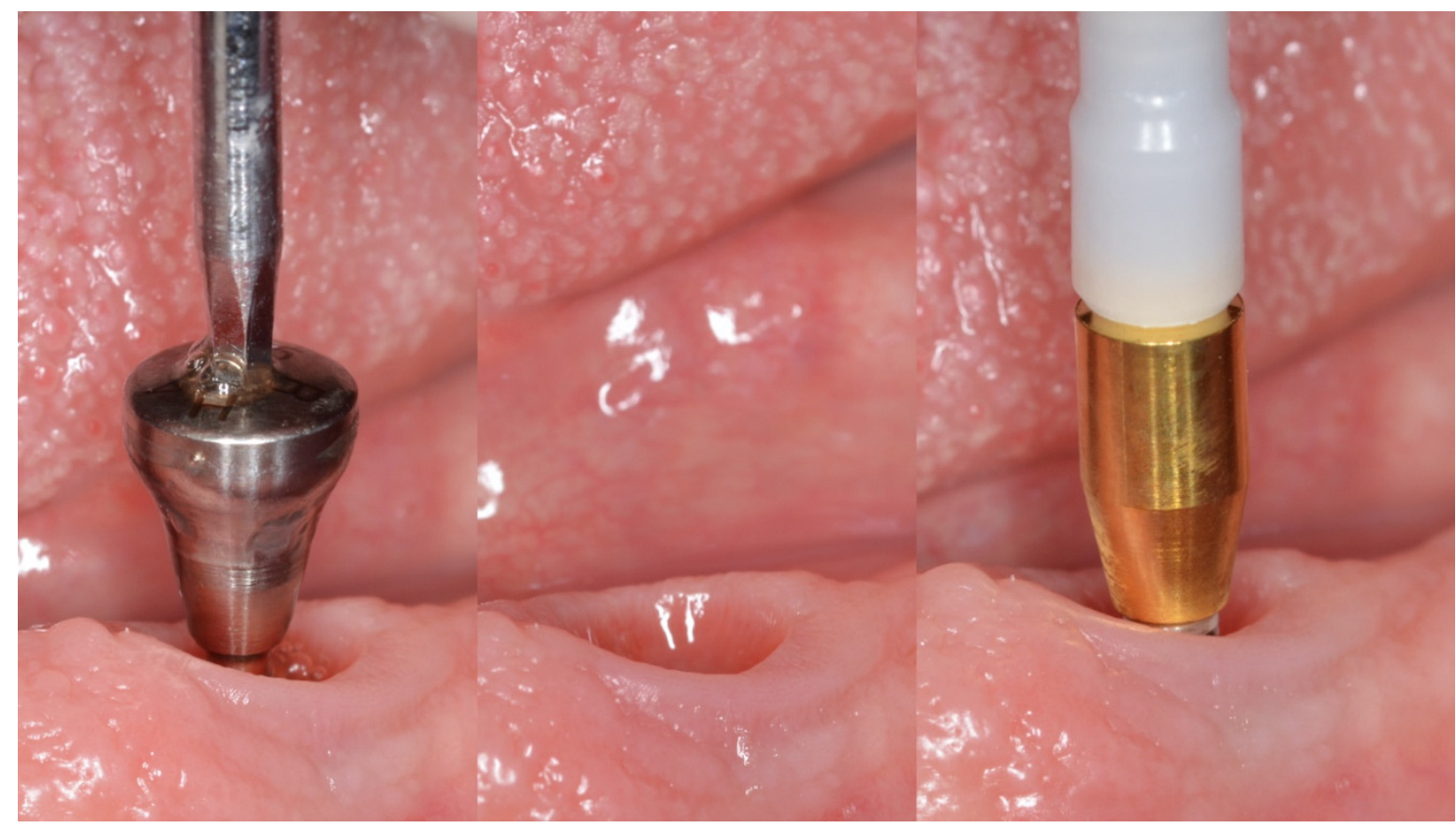

Figure A16. Healing abutment removal and Equator (Rhein83, Bologna, Italy) positioning.

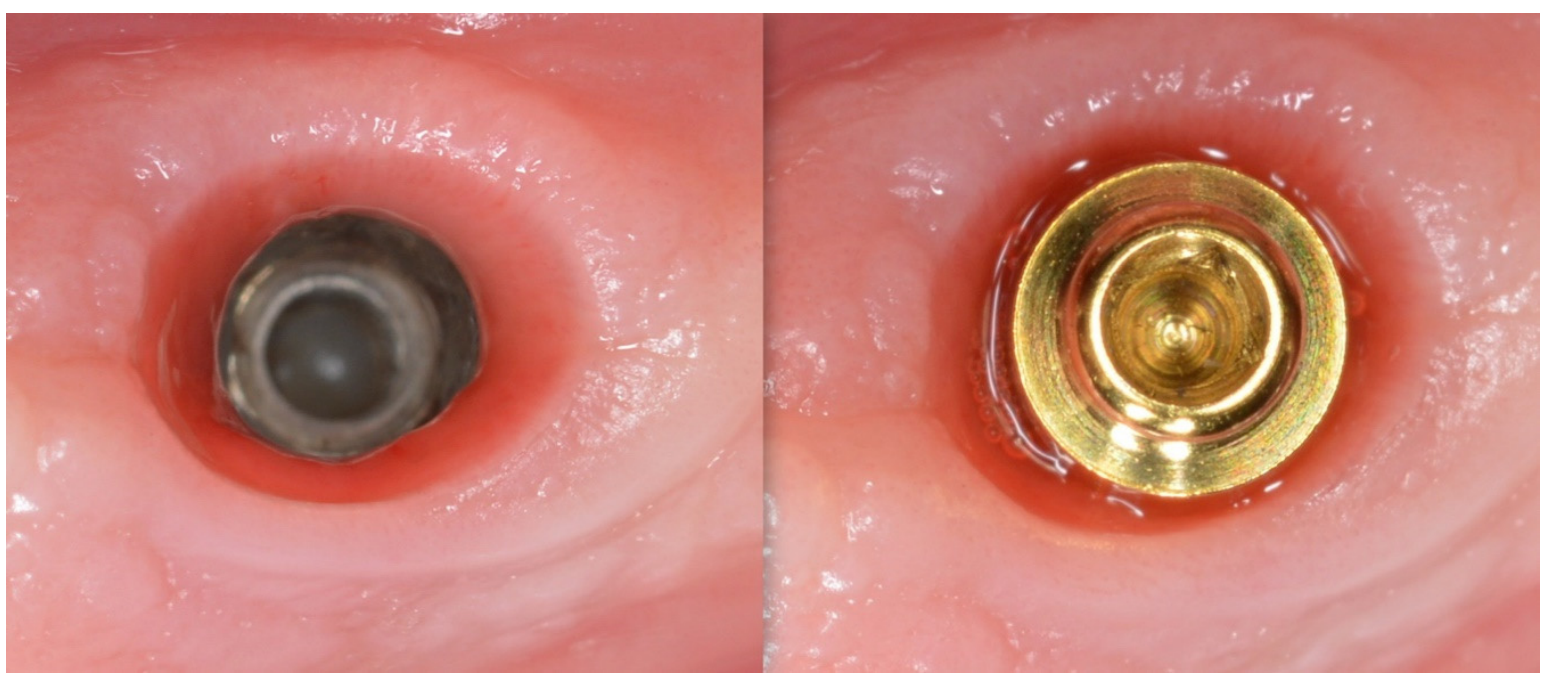

Figure A17. Fixture healthy tissue detail and Equator (Rhein83, Bologna, Italy) detail. 


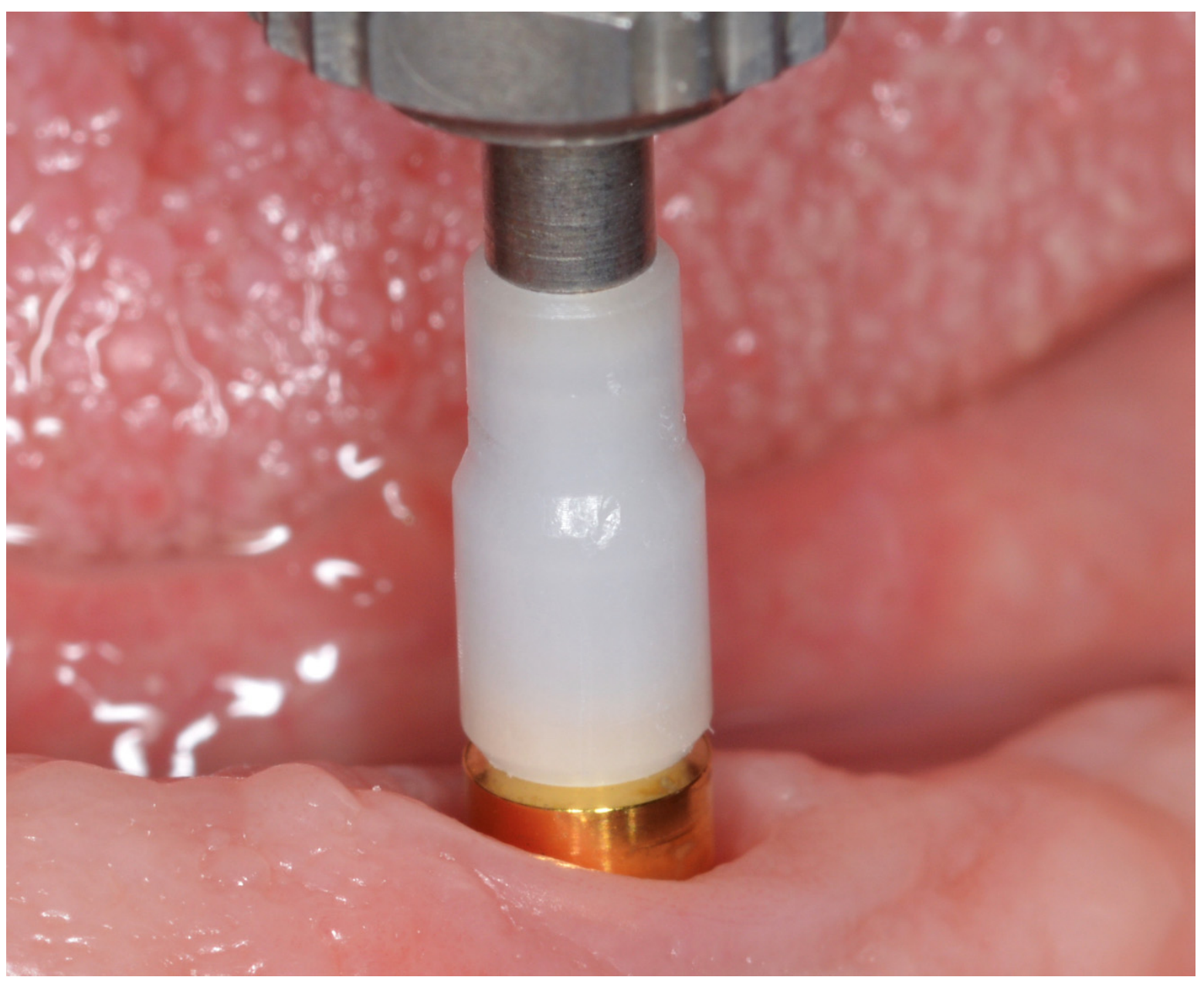

Figure A18. Equator (Rhein83, Bologna, Italy) positioning.

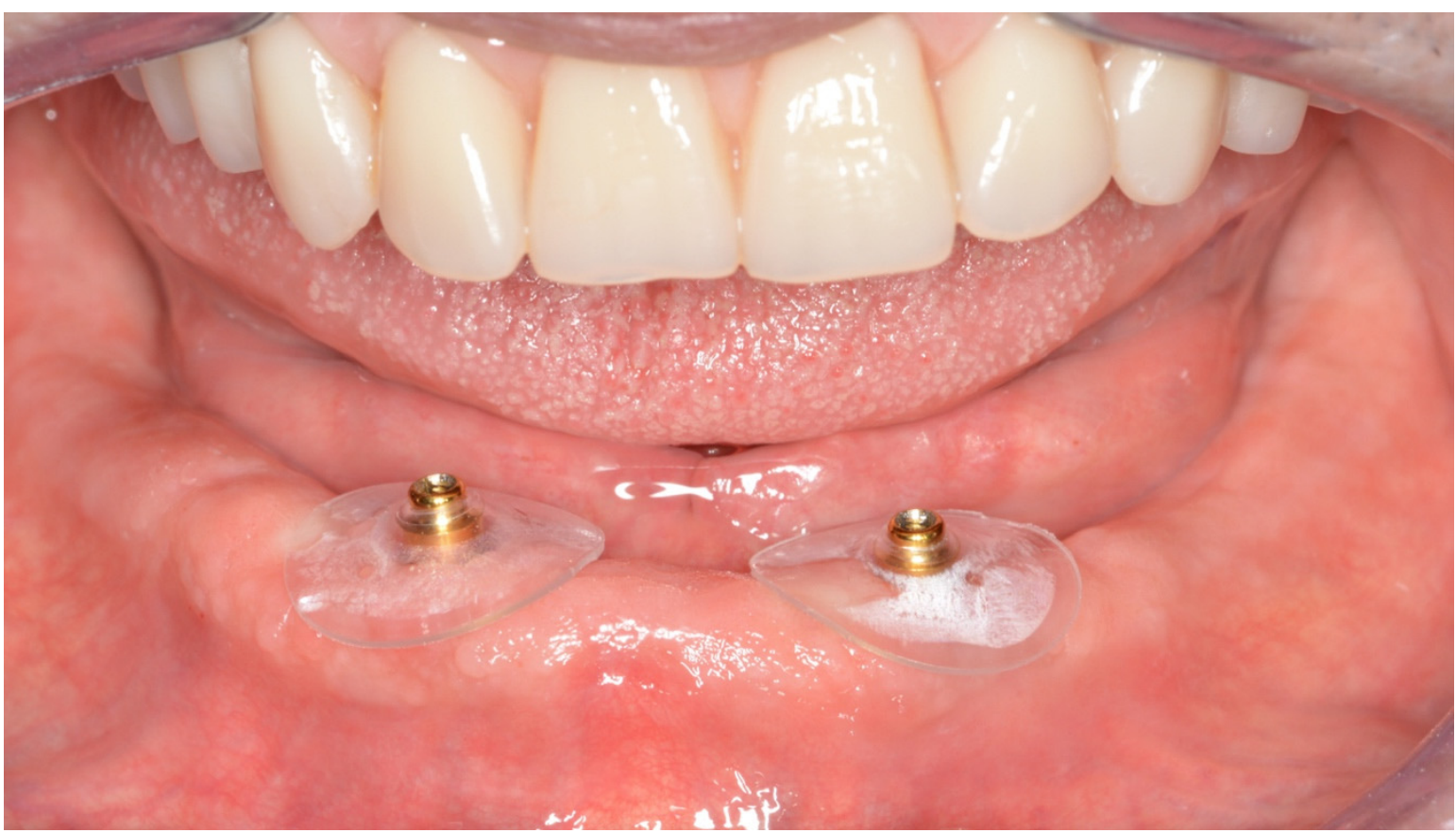

Figure A19. Separator disk positioning. 


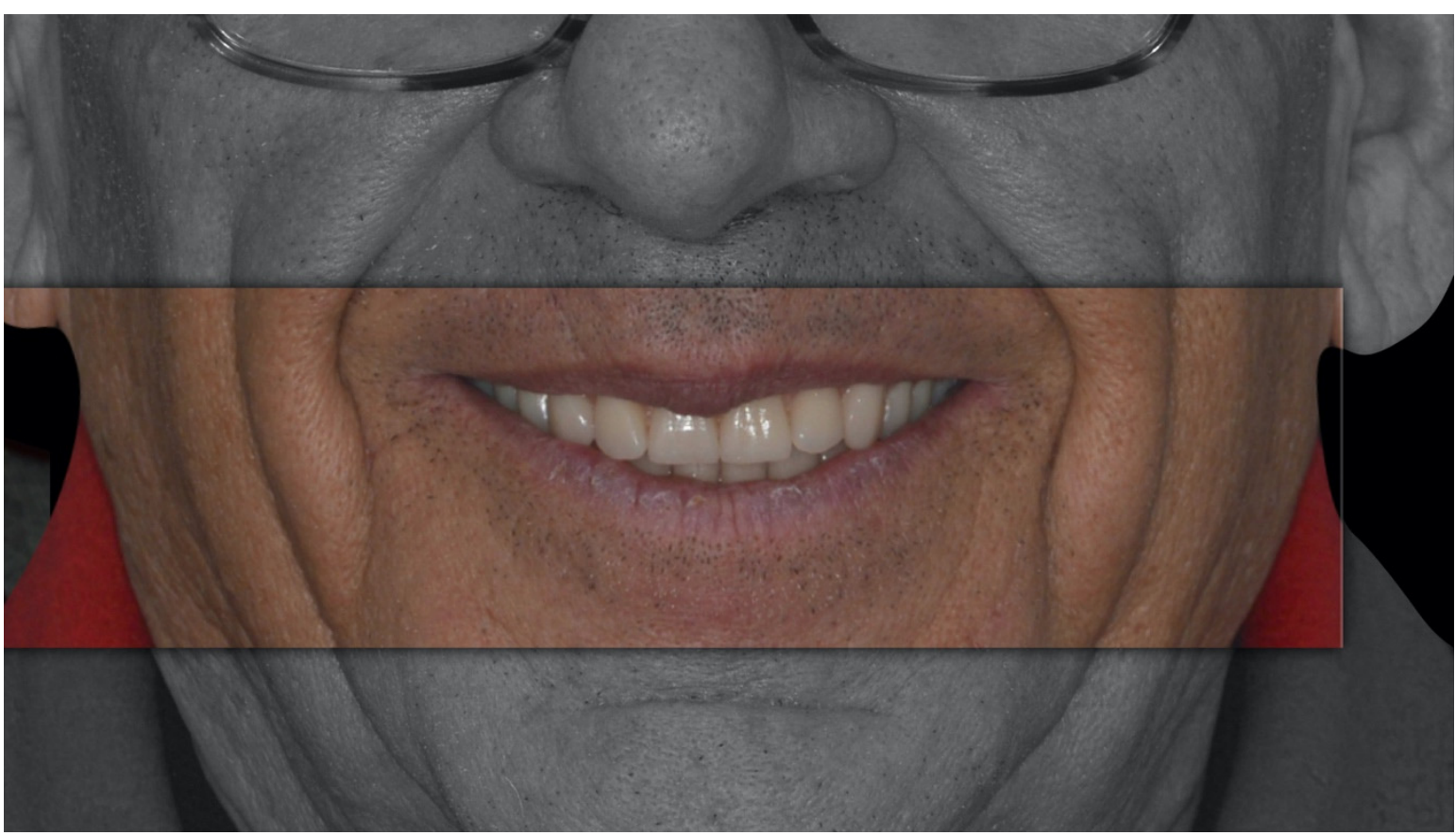

Figure A20. Final result.

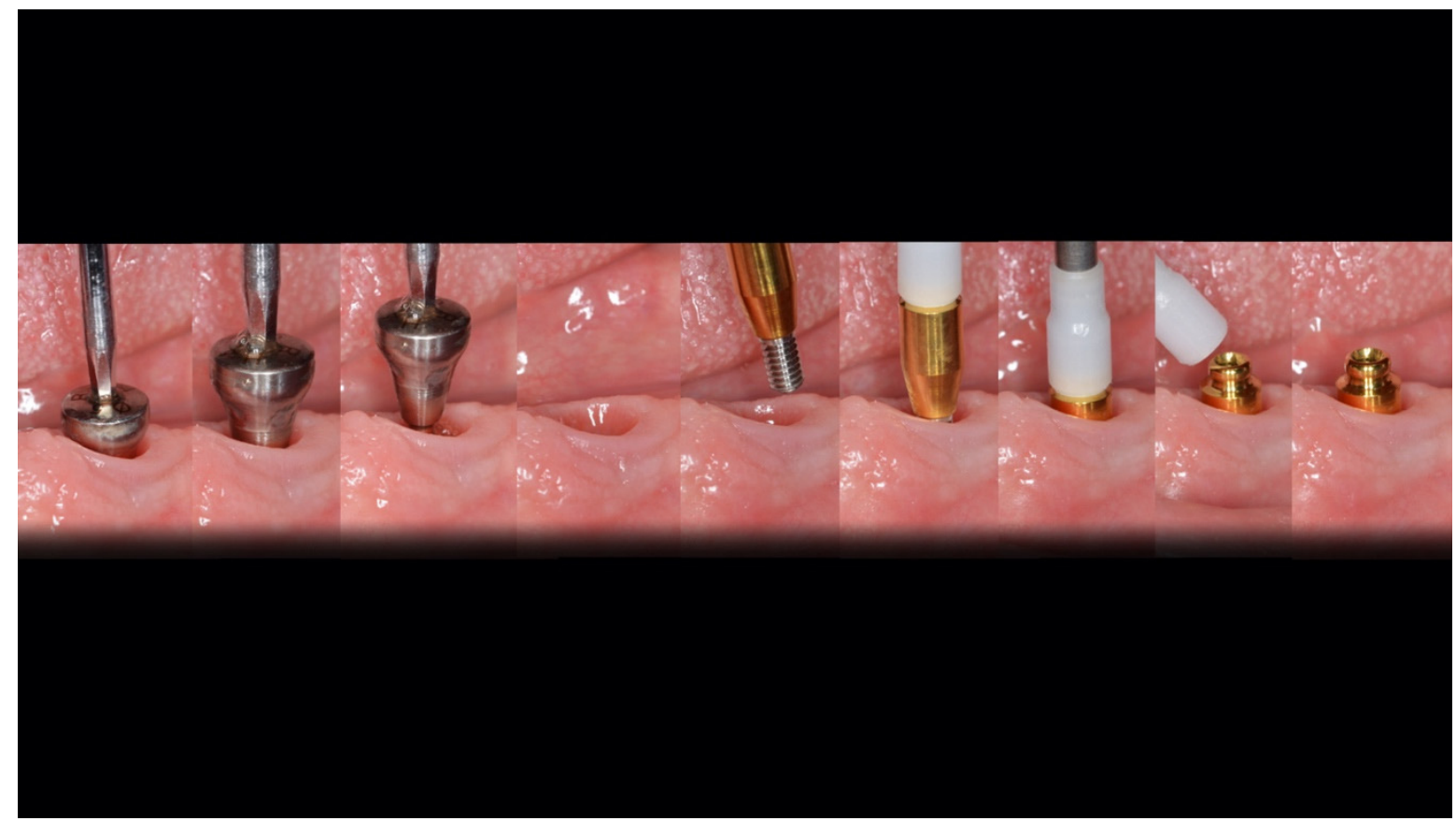

Figure A21. From healing abutment removal to Equator (Rhein83, Bologna, Italy) positioning phases.

\section{References}

1. Zitzmann, N.U.; Marinello, C.P.; Sendi, P. A cost-effectiveness analysis of implant overdentures. J. Dent. Res. 2006, 85, 717-721. [CrossRef] [PubMed]

2. Albrektsson, T.; Blomberg, S.; Branemark, A.; Carlsson, G.E. Edentulousness-an oral handicap. Patient reactions to treatment with jawbone-anchored prostheses. J. Oral Rehabil. 1987, 14, 503-511. [CrossRef] [PubMed]

3. Ellis, J.S.; Burawi, G.; Walls, A.; Thomason, J.M. Patient satisfaction with two designs of implant supported removable overdentures; ball attachment and magnets. Clin. Oral Implants Res. 2009, 20, 1293-1298. [CrossRef] [PubMed] 
4. Harris, D.; Höfer, S.; O’Boyle, C.A.; Sheridan, S.; Marley, J.; Benington, I.C.; Clifford, T.; Houston, F.; O'Connell, B. A comparison of implant-retained mandibular overdentures and conventional dentures on quality of life in edentulous patients: A randomized, prospective, within-subject controlled clinical trial. Clin. Oral Implants Res. 2011, 24, 96-103. [CrossRef]

5. Bramanti, E.; Matacena, G.; Cecchetti, F.; Arcuri, C.; Cicciù, M. Oral health-related quality of life in partially edentulous patients before and after implant therapy: A 2-year longitudinal study. ORAL Implantol. 2013, 6, 37-42. [CrossRef]

6. Germano, F.; Bramanti, E.; Arcuri, C.; Cecchetti, F.; Cicciù, M. Atomic force microscopy of bacteria from periodontal subgingival biofilm: Preliminary study results. Eur. J. Dent. 2013, 7, 152-158. [CrossRef]

7. Maiorana, C.; Beretta, M.; Grossi, G.B.; Santoro, F.; Herford, A.S.; Nagursky, H.; Cicciù, M. Histomorphometric evaluation of anorganic bovine bone coverage to reduce autogenous grafts resorption: Preliminary results. Open Dent. J. 2011, 5, 71-78. [CrossRef]

8. Thomason, J.M.; Kelly, S.A.M.; Bendkowski, A.; Ellis, J.S. Two implant retained overdentures-A review of the literature supporting the McGill and York consensus statements. J. Dent. 2012, 40, 22-34. [CrossRef]

9. Tallarico, M.; Vaccarella, A.; Marzi, G.C. Clinical and radiological outcomes of 1- versus 2-stage implant placement: 1-year results of a randomised clinical trial. Eur J. Oral Implant. 2011, 4, 13-20.

10. Babbush, C.A.; Tallarico, M. Twelve-year clinical and radiological results of maxillary and mandibular implant-retained bar overdentures carried out on oxidized (TiUnite) replace select implants: A clinical case. J. Oral Implantol. 2013, 39, 737-742. [CrossRef]

11. Scrascia, R.; Venezia, P. Healthcare meets Aesthetics: New approaches to the complex oral rehabilitations with implant-supported dental prostheses. Australas. Med J. 2017, 10, 537-541. [CrossRef]

12. Portelli, M.; Militi, A.; Logiudice, A.; Nucera, R. An Integrated Approach, Orthodontic and Prosthetic, in a Case of Maxillary Lateral Incisors Agenesis. Prosthesis 2019, 1, 3-10. [CrossRef]

13. Ortensi, L.; Vitali, T.; Bonfiglioli, R.; Grande, F. New Tricks in the Preparation Design for Prosthetic Ceramic Laminate Veeners. Prosthesis 2019, 1, 29-40. [CrossRef]

14. McGrory, A.C.; McGrory, B.J.; Rana, A.; Babikian, G. Incidence of Heterotopic Ossification in Anterior Based Muscle Sparing Total Hip Arthroplasty: A Retrospective Radiographic Review. Prosthesis 2019, 1, 11-15. [CrossRef]

15. Frossard, L.; Jones, M.W.M.; Stewart, I.; Leggat, P.A.; Schuetz, M.; Langton, C. Kinetics of Lower Limb Prosthesis: Automated Detection of Vertical Loading Rate. Prosthesis 2019, 1, 16-28. [CrossRef]

16. Cicciù, M. Prosthesis: New Technological Opportunities and Innovative Biomedical Devices. Prosthesis 2019, 1, 1-2. [CrossRef]

17. Cicciù, M.; Cervino, G.; Milone, D.; Risitano, G. FEM Investigation of the Stress Distribution over Mandibular Bone Due to Screwed Overdenture Positioned on Dental Implants. Materials 2018, 11, 1512. [CrossRef]

18. Xhanari, E.; Scrascia, R.; Kadiu, B.; Tallarico, M. Two implants supporting a mandibular overdenture to rehabilitate Cawood and Howell Class V and VI patients: A proof-of-concept study. J. Oral Sci. Rehabilit. 2017, 3, 52-59.

19. Scrascia, R.; Martinolli, M.; Venezia, P.; Casucci, A.; Ortensi, L.; Tallarico, M. Feasibility of Low Profile Attachments to Improve Quality of Life on Patients with Implant-Retained Mandibular Overdenture: 1-Year Preliminary Results of a Multicenter Prospective Case Series Study. J. Oral Health Dental Manag. 2018, 17, 5.

20. De Stefano, R. Psychological Factors in Dental Patient Care: Odontophobia. Medicina 2019, 55, 678. [CrossRef]

21. Bryant, S.R.; Walton, J.N.; MacEntee, M.I. A 5-year randomized trial to compare 1 or 2 implants for implant overdentures. J. Dent. Res. 2015, 94, 36-43. [CrossRef] [PubMed]

22. Fiorillo, L. Chlorhexidine Gel Use in the Oral District: A Systematic Review. Gels 2019, 5, 31. [CrossRef] [PubMed]

23. Troiano, G.; Laino, L.; Cicciu, M.; Cervino, G.; Fiorillo, L.; D’Amico, C.; Zhurakivska, K.; Lo Muzio, L. Comparison of Two Routes of Administration of Dexamethasone to Reduce the Postoperative Sequelae After Third Molar Surgery: A Systematic Review and Meta-Analysis. Open Dent. J. 2018, 12, 181-188. [CrossRef] [PubMed]

(C) 2020 by the authors. Licensee MDPI, Basel, Switzerland. This article is an open access article distributed under the terms and conditions of the Creative Commons Attribution (CC BY) license (http://creativecommons.org/licenses/by/4.0/). 